\title{
Lactic Acid Bacteria as Markers for the Authentication of Swiss Cheeses
}

\author{
Petra Lüdin*, Ueli von Ah, Deborah Rollier, Alexandra Roetschi, and Elisabeth Eugster
}

\begin{abstract}
The manufacture of traditional Swiss-type cheeses adheres to strict rules, so as to guarantee quality and purity of the end product. This raises production costs and means consumers pay more. It also opens the door to cut-rate forgeries claiming to be made to the stringent standards and causing considerable economic losses to the entire dairy sector. In order to combat product counterfeiting, Agroscope has developed proof-of-origin cultures that allow the identification of copycats. Carefully selected lactic acid bacteria, having uniquely located insertion sequence elements, are proliferated by fermentation and subsequently dried by lyophilization. The proof-of-origin culture is added during the cheese production process and sustains maturation. These so-called 'biological markers' can be traced using polymerase chain reaction (PCR) methods, which allow authentication even if the cheese is cut into pieces or grated. They do not lead to any alteration of the cheese's taste or texture, and are compatible with the strict 'protected designation of origin' (PDO) specifications. The proof-of-origin cultures are used for the protection of several traditional Swiss-cheese varieties, such as Emmental PDO, Tête de Moine PDO, and Appenzeller ${ }^{\circledast}$. A market survey of Emmental PDO showed that the system is effective in revealing fraud and has the power to enforce corrective measures.
\end{abstract}

Keywords: Authentication $\cdot$ Cheese $\cdot$ Lactic acid bacteria $\cdot$ Proof-of-origin

\section{The Need for Authentication of Swiss Cheeses}

The liberalization of the cheese market in 2007 put some pressure on the traditional domestic cheese varieties. One general answer was the introduction of 'protected designation of origin' (PDO, see Textbox $)^{[1]}$ and other labels. The idea was to protect products that come from a specific region and have a long tradition and which possess characteristics that are influenced considerably by the area of origin. In order to guarantee high quality of PDO products, cheese makers have to follow strict rules that are described in the PDO specifications. Because of the traditional methods used in their manufacture, PDO and branded products achieve a high value-added status on the market. Obviously, production costs are higher than for industrial cheeses, and this opens the door to counterfeiters, resulting in increased economic losses. On supermarket shelves worldwide, an estimated $10 \%$ of cheese labeled as Swiss-made Emmental is not real and costs several millions of Swiss francs annually. ${ }^{[2]}$ The demand for a

\footnotetext{
${ }^{\star}$ Correspondence: P. Lüdin
}

Agroscope Institute for Food Sciences IFS Schwarzenburgstrasse 161, CH-3003 Bern E-mail: petra.luedin@agroscope.admin.ch reliable proof-of-origin system and framework for legal conditions to combat abuses is obvious.

The proof-of-origin system developed by Agroscope to identify a PDO/branded cheese has been used with Emmental AOP and Tête de Moine AOP since 2011 and 2013, respectively. June 2015 saw the launch of the third proof-of-origin culture, this time for Appenzeller ${ }^{\circledR}$.

\section{Different Options for the Proof of Origin for Cheese}

There are different options for the authentication of cheese. Using a casein tag on the top of the whole cheese or print- ing a special pattern on the cheese surface are possibilities for protection when the cheese is used as a whole wheel. It is useless for grated, sliced or cut cheeses. Therefore, a matrix-specific method is needed. Pillonel et al. searched for parameters that would enable a geographic classification of Emmental cheeses. Using chemometric analysis, they were able to distinguish Emmental PDO made in Switzerland from that produced in different European regions. ${ }^{[3]}$ But this method is very expensive and time-consuming. The analysis of stable isotopes has also been used widely in authenticity control and origin determination of food, and has been applied to distinguish cheeses from different countries. ${ }^{[4,5]}$ Several analytical

Labels for Indication of Origin (PDO/PGI)

English PDO = Protected Designation of Origin; PGI = Protected Geographical Indication

French: $\mathrm{AOP}=$ Appellation d'Origine Protégée; IGP = Indication Géographique Protégée

German: GUB = geschützte Ursprungsbezeichnung; GGA = geschützte geographische Angabe

The protection of designation for agricultural products aims to protect consumers and cheese manufactures from fraud and unfair competition. The name of an area or traditional names of specialties with a strong link to their region or origin can be protected. Protected names are only allowed to be used by producers of the defined geographical area which adhere to the strict rules of the specification.

In products with a PDO, everything from the raw material to the processing and the final product, comes from one clearly defined region of origin. Specialties with a PGI are either manufactured, processed or prepared at their place of origin.

http://www.aop-igp.ch/en-home

http://www.blw.admin.ch/themen/00013/00085/00094/index.html?lang $=$ de 
approaches have been proposed for recognizing imitations of Grana Padano PDO cheeses. Promising results were achieved by analyzing the free amino-acid composition in combination with the identification of a specific peptide and the measurement of the alkaline phosphatase activity. The latter two parameters, however, are only found in the rind or just below the rind, and therefore this method is not suitable for every cheese sample. ${ }^{[6]}$ Attenuated total reflectance Fourier transform infrared spectroscopy (ATR-FTIR) combined with chemometric analysis also gives good specification about the overall differences between hard cheeses. ${ }^{[7]}$ However, none of the described techniques is a stand-alone method for assuring a correct identification of Grana Padano PDO. They need to be complemented with other analytical methods in order to enhance the reliability of identification, which increases analytical costs and necessary time.

Some parameters have been found to be suitable for distinguishing Swiss cheese from foreign products. ${ }^{[8]}$ Additives such as natamycin (a fungicide for protecting the smear against molds), lysozyme (a preservative for preventing late blowing) or nitrite (to prevent butyric acid fermentation) are authorized by the EU and Swiss legislations, but many cheese organizations in Switzerland have renounced their use voluntarily, so as to offer a completely natural product to the consumer. The recognition of such additives gives a first indication of the origin of a cheese, but is not sufficient for an error-free proof of origin and must be combined with other methods. This can again lead to time-consuming and expensive testing.

The identification of proteins or DNA sequences in an existing food matrix are a further option for the validation of food authenticity.[9] DNA-based marker systems seem especially appropriate, because only small traces of organic material are needed for DNA detection and DNA is generally more informative than proteins. Methods that use polymerase chain reactions (PCRs) or DNA barcoding are already used for seafood or meat traceability, and also have been proposed for dairy products. ${ }^{[9]}$ Therewith it is possible to determine the animal species from which the milk is obtained, which can be useful, for instance, in Mozzarella cheese, which should only consist of buffalo milk and should not be stretched with cow milk. ${ }^{[10]}$ Mauriello et al. ${ }^{[11]}$ were able to distinguish between cheeses with natural whey cultures (NWC) and curd obtained from milk without NWC, which is an interesting process-specific feature. Arcuri et al. ${ }^{[12]}$ have proposed using $16 \mathrm{~S}$ rDNA fingerprinting of bacterial communities by PCRs, followed by denaturing gradient gel electrophoresis (DGGE), for the geographical traceability of Brazilian Minas cheese. The band profiles have been used as biological bar codes to differentiate between the four different regions of production, as well as for recognizing cheese from either pasteurized or raw milk.

Another option is the addition of encapsulated DNA nanoparticles ${ }^{[13]}$ to the vat milk. However, because PDO specifications require that only natural ingredients, originating from the geographical region, be allowed for the manufacturing of PDO cheeses, no additives are permitted. Encapsulated DNA nanoparticles are therefore not an option for labelled food stuffs.

The risk of fraud is generally highest in the geographical regions directly adjacent to the defined area where PDO or labelled food products are manufactured. The know-how exists, and forgers can take advantage of the popularity of the label. For combatting fraud that is taking place within or close to a protected area, the determination of the previously described features are not sufficient. Another option for the proof of origin of labelled cheese that is specific for a selected group of cheese makers is therefore needed.

\section{Traceable Bacteria Added during the Cheese-making Process}

Agroscope has developed a new method for verifying the authenticity of labelled cheese varieties. This process includes the addition of natural lactic acid bacteria to the vat milk so that it can be traced back, even in grated or processed cheese, by means of rapid and sensitive PCR tests (see Textbox). ${ }^{[14]}$ Natural lactic acid bacteria play an important role in the manufacture of cheese. They are most notably responsible for a proper acidification and coagulation of the milk. ${ }^{[15]}$ They are also essential for flavor development, gas and hole production, and dough properties.
Many lactic acid bacteria are naturally present in raw milk and the cheese makers' environment, or are added explicitly in the form of starter or natural whey cultures. ${ }^{[16]}$ Therefore, bacteria naturally present in milk and cheese from the region of origin can be isolated and selected as markers. Lactic acid bacteria are especially suitable, as a huge biodiversity can be found in the cheese environment and billions are present per gram of cheese. [17] Some of these bacteria survive scalding temperatures during cheese making and are stable during long maturation periods, and several do not change the cheese's taste, texture or smell. More than 10,000 bacterial isolates collected during the last 100 years are preserved at Agroscope's strain collection, and are an important basis for selecting suitable marker bacteria for the development of proof-of-origin cultures.

\section{Identification of Suitable Lactic Acid Bacteria}

In order to develop a strain-specific detection method, the positions of insertion sequences (ISs) on the genome are used. ISs are distinct genetic units of less than $2.5 \mathrm{~kb}$ of DNA with simple genetic organization, and that can change their position within the genome. Lactic acid bacteria can be typed at the intraspecies level using restriction fragment length polymorphism (RFLP) associated with the presence of multiple IS elements. ${ }^{[14]}$ This indicates that IS elements are suitable for describing unique parts on the genome. A method using IS elements for the identification of lactic acid bacteria has been developed and patented by Agroscope. ${ }^{[18]}$ For this purpose, DNA of the target strain is extracted and the availability of such uniquely located IS elements is checked using polymerase chain reactions (PCRs). Therefore, different primers, alone or in combination, that target IS elements are applied, allowing

\section{Polymerase Chain Reaction (PCR)}

PCR is a rapid and selective method for the amplification (generation of copies) of DNA segments without cells. DNA is incubated together with free nucleotides, an enzyme called DNA polymerase, and primers that are complementary to the DNA strand under specific thermal cycling conditions in the PCR machine. Initially, the mixture is heated to denature (or separate) the DNA double strands of the double helix into single-strands that serve as templates for the formation of new double strands. The mixture is then cooled so that the primers can bind. The primers determine the DNA sequence that is amplified, because they bind to a specific region. As the next step, DNA polymerase adds the nucleotide that matches the template and synthesizes new strands of DNA. PCR then continues with additional cycles that repeat the same steps, and the DNA target is amplified exponentially millions of times.

Because PCR amplifies the regions of DNA that it targets, PCR can be used to analyze extremely small amounts of sample. Larger DNA amounts can better be analyzed and, for instance, made visible by gel electrophoresis. Therefore, it is a simple and quick method for checking if a certain DNA fragment is present or not. 
amplification to occur and obtaining PCR products unique for the specific strain. The accumulated PCR amplification product is detected and isolated by gel electrophoresis. The identified unique PCR product is sequenced and new primers are designed for targeting this DNA fragment (Fig. 1).

In the next step, strain specificity has to be assessed. Therefore, the newly designed primers are used to run hundreds of PCRs to check for the presence or absence of the potential unique sequence in other related strains and cheese samples. Only if this step is successful, meaning that a unique sequence is present in only one strain, the bacteria can be considered for further tests in cheese.

Nowadays, it is possible to identify unique sequences by applying whole genome sequencing together with bioinformatic tools. However, a considerable amount of genome sequences have to be available for comparison, and therefore a large strain collection of the desired species is required. Next-generation sequencing techniques are available at Agroscope and have been applied for some species already. They will probably replace the timeconsuming PCR product-based method for the identification of unique sequences.

\section{Process Development and Biomass Production}

Current starter cultures, as well as presently-used proof-of-origin cultures, consist mainly of lactic acid bacteria (LAB). ${ }^{[17]}$ They are fastidious in growth, and therefore process development is a demanding task, especially with regard to cultures with a longer shelf life (up to 24 months).[19-21] Until the 1980s, all cultures were sold in liquid or frozen form. Since then, more and more cultures are sold in freeze-dried form. This allows longer transportation distances and the cultures can be stored at $4{ }^{\circ} \mathrm{C}$ or even at room temperature without losing activity for a longer period of time.

Freeze drying is a well-known process in the manufacturing of various pharmaceutical and food products. ${ }^{[22]}$ Freeze drying of bacteria on a larger scale was developed later because enzymes or antibodies of the bacteria are very sensitive. ${ }^{[22]}$ Additionally, the survival rate after freeze drying depends strongly on the fermentation process for biomass production. ${ }^{[23-25]}$

\subsection{Medium and Fermentation Process Optimization}

This part of process development is similar for liquid, frozen, and freeze-dried cultures. However, for the proof-of-origin cultures, the main aim was to achieve a high yield in biomass and to make sure that the selected strains would not alter the

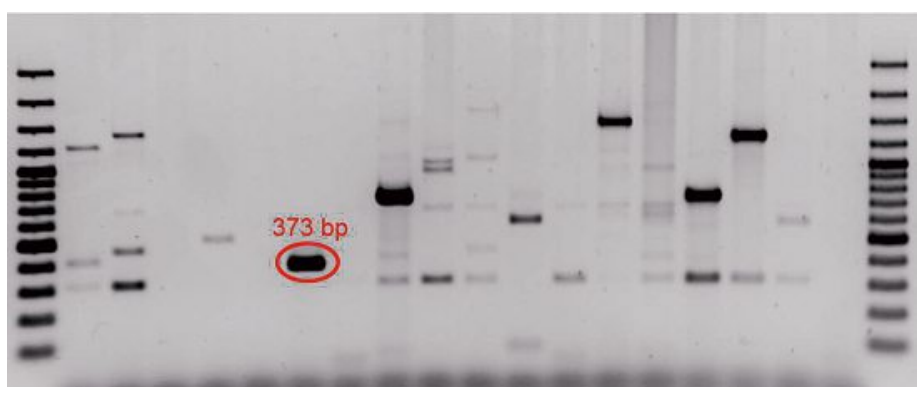

Fig. 1. Example of separated PCR products after gel electrophoresis. Left and right lanes represent the DNA-ladder, lanes in between show PCR products of different strains. The band indicated with $373 \mathrm{bp}$ shows a unique fragment only found in one strain. Picture: A. Roetschi, Agroscope.

cheese quality. Particularly, the physiological state of the bacteria, and therefore its surviving rate after freeze drying, depends on the fermentation process.

In contrast to other bacteria, such as the well-explored $E$. coli, LAB cannot synthesize all compounds required for growth (e.g. certain amino acids). ${ }^{[26]}$ It is therefore necessary to evaluate several media to optimize the biomass production. Such complex media are usually based on cheap byproducts from cheese production, such as whey or whey permeate. ${ }^{[27,28]}$ Additionally, specific compounds are added to the recipe in order to increase survival rates of the bacteria in subsequent production processes. ${ }^{[23,29,30]}$

The process parameters for the fermentation have to be determined as well. They are based on optimal growth parameters of the specific strain. The most important parameters for fermentation are $\mathrm{pH}$, temperature, and aeration ${ }^{[31,32]}$ as well as the fermentation time, which influence the survival as well as the activity of the strain. [33]

\subsection{Freeze-drying Process}

After growth in the optimized fermentation process, the bacteria must be concentrated by centrifugation. Since the freezing process during lyophilization is the most stressing part for the bacteria, they have to be protected. This is normally achieved by using so-called cryo-protectants. Those protectants increase survival rates by avoiding formation of ice crystals inside the cells as well as in subsequent refrigerated storage (Fig. 2).

For LAB used in the dairy industry, skim milk powder is commonly used as a drying medium; it prevents cellular injury by stabilizing the cell membrane and creates a porous structure in the freeze-dried product that makes rehydration easier, [24] which is another important factor for the survival of the bacteria in the final product. Several sugars, such as saccharose or maltodextrin, are also commonly used as protective media, either alone or in combinations with skim milk. Sugars are pre- ferred due to their relatively low costs, chemically innocuous nature, and common use in the food industry. Sugar residues from the fermentation medium can have a similar effect.

The parameters for the freeze-drying process have to be optimized individually for each strain. The first step of freezing is already crucial, as the right freezing rate has to be applied. Bacteria can be frozen at $-196{ }^{\circ} \mathrm{C}$ in liquid nitrogen, or more slowly at $-40{ }^{\circ} \mathrm{C}$. The freezing rate determines the formation of ice crystals in the cells, and consequently the mechanical damage to the cell membrane. For the sublimation step, the temperature and vacuum have to be optimized.

The complete process-development work has to be done before testing the proof-of-origin culture, as every change in a process parameter can have an influence on the traceability of the culture in the cheese.

\section{Tests at Pilot-plant Level and in Practice}

Once a strain with a unique sequence appropriate for detection by PCR is identified and its production process is developed, the behavior of the strain in cheese matrices needs to be investigated.

Therefore, freshly produced proof-of-

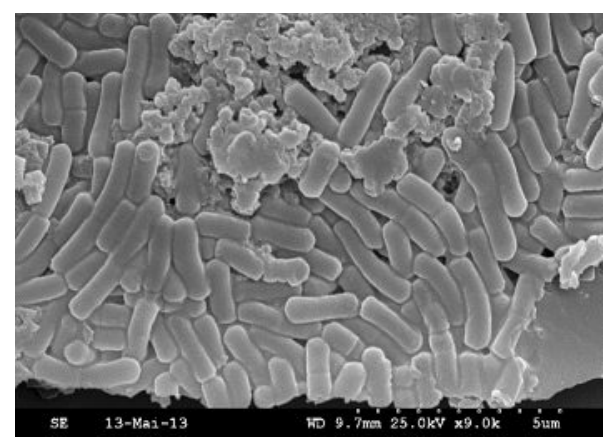

Fig. 2. Lactic acid bacteria embedded in cryoprotectant. 10'000x enlargement under the scanning electron microscope (SEM). Picture: B. Frey, University of Bern, Switzerland. 
origin cultures, including selected marker bacteria, are applied at the pilot-plant cheese factory. Eight cheeses can be produced in parallel under standardized conditions and are ripened in the cellar. During the cheese manufacturing process, the proof-of-origin culture is added directly into the milk at the same time as the starter cultures are added. The marker strains survive the entire process and remain in the cheese curd. The maturation time depends on the cheese type, and can range from a couple of months for a semi-hard cheese to 12 months or more for a hard cheese. This can be very challenging for the stability of the marker bacteria. During the maturation phase, cheese samples are regularly taken and analyzed in the lab for their quality and the traceability of the marker bacteria. The PCR signal must be stable during the ripening time, in order to be sure that the marker bacteria are not degraded in the cheese matrix. On every cheese probe, total DNA is extracted and analyzed by specific PCRs for the unique genome sequences of the marker bacteria. Cheese quality has to be examined carefully in order to be sure that the marker bacteria do not have a significant impact on the cheese. Therefore the wheel can be $\mathrm{X}$-rayed in order to observe eye formation, and typical cheese parameters, such as water content, amounts of carboxylic acids, total free amino acids and protein degradation are measured and compared to the control cheese. A visual analysis of the cut cheese, followed by a sensorial test by an expert panel, are performed at the end of the ripening time. If all requirements are met at pilot-plant level, first trials in practice are conducted with some selected cheese factories. The ripened cheeses from these factories are also controlled to make sure that the requirements are met in the practice as well. Normally, the transfer from pilot-plant trials into practice takes place without difficulties.

\section{Risk of Duplication of the Proof- of-origin Culture}

The risk that one can copy and duplicate the proof-of-origin culture is estimated as very low. First of all, a huge series of tests are performed to be sure that the PCR product represents a unique sequence which is present in only one strain. Secondly, the system using IS elements for the identification of lactic acid bacteria has been developed and patented by Agroscope. Thirdly, Agroscope provides the proof-oforigin culture only to authorized cheese manufacturers. The authorization must be obtained from the interprofessional cheese organization. Fourthly, cheese manufacturers only get the necessary amount of the proof-of-origin culture which they need for the transformation of a certain quantity of milk. This means that the delivered quantity of proof-of-origin culture is based on the amount of processed milk. And last but not least, the proof-of-origin culture consists of more than one traceable strain. The composition of the mixture is changed (rotation principle) from time to time in accordance with the interprofessional cheese organization.

\section{Results from Retail Samples}

Once the cheese makers apply proofof-origin cultures for the protection of PDO products, the enforcement authorities can have samples analyzed for the presence of the marker bacteria. Suspicious samples are analyzed within 2 to 3 days, and larger surveys can take place periodically in order to check the proof of origin in retail samples. Therefore, about $10 \mathrm{~g}$ of a cheese sample is prepared in the stomacher, cheese fat is removed, and cheese proteins are precipitated in order to extract good-quality DNA that is suitable for conducting a quantitative PCR analysis with the marker-specific primers.

Table 1 shows the results of the last control of Emmental PDO cheese, which was performed by Agroscope. Twentyfour packaged cheeses and 14 cheeses sold over the counter were analyzed. The four control cheeses additionally included were all negative for the presence of the marker bacteria. Although processed cheese is not part of the validated method, four samples were included as well in the test. The marker bacteria apparently survived further processing of the cheese, and therefore were clearly detectable in all samples of processed cheese. All other probes were positive except two. Probe L30-13 was a mixture of grated cheese
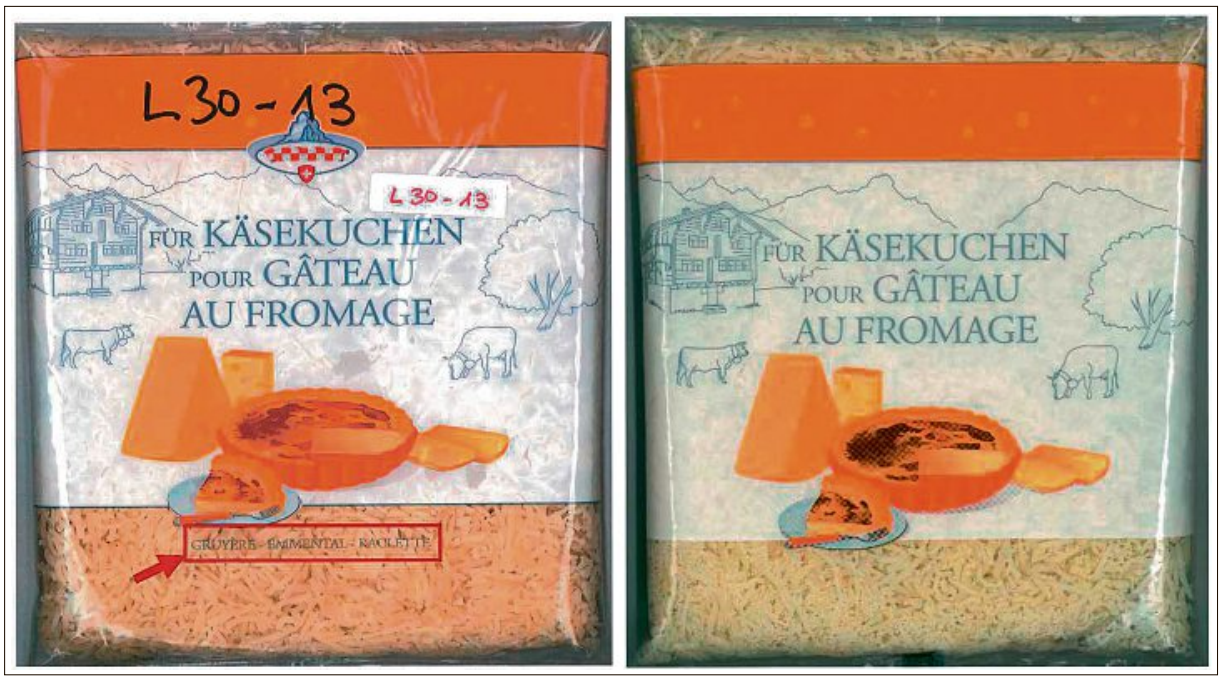

Fig. 3. left: Bag with grated cheese mixture for the analysis in 2013. Right: Adapted cheese pack-

aging in 2015.

suitable for baked cheesecakes. It was labelled 'Gruyère - Emmental - Raclette'. A closer look at the declaration clarified that Emmental PDO did not have to be present especially, because the sample was a 'preparation of Swiss and foreign grated semi-hard and hard cheese'. The presence of the Swiss cross on the top side of the package may lead the consumer to expect real Swiss Emmental PDO, and even if this is not illegal, it is confusing. Nevertheless, thanks to the proof-of-origin test, discussions were raised, and the manufacturer recognized the counterfeiting part of the label and adapted it later (Fig. 3).

For the second case with a negative result, L40-13, the cheese factory was identified and taken to task. The responsible cheese maker admitted that he added too little of the proof-of-origin culture. As a consequence, the applied culture concentration was too low for the necessary sensitivity of the PCR and the signal was lost.

Although the checks in 2013 did not reveal deliberate counterfeits, it demonstrated that the technology of using marker bacteria for the proof of origin for Swisstype cheeses is a reliable method that leads to the detection of fraud. However, the most important aspect of introducing marker bacteria into cheese is probably fraud prevention. Knowing that counterfeiters can be caught and taken to justice makes cheese counterfeiting much less attractive, and saves millions for the cheese makers and interprofessional cheese organizations. This has also been recognized by other cheese organizations, and more lactic acid bacteria as proof-of-origin cultures for the authentication of labelled Swiss cheeses will follow in the future.

Received: December 14, 2015

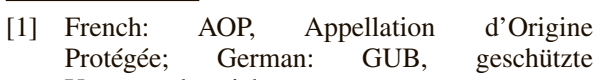
Ursprungsbezeichnung 
Table 1. PCR results indicating the presence or absence of the marker bacteria in 38 cheeses, 4 control cheeses and 4 processed cheeses during a market control for Emmental PDO.

\begin{tabular}{|c|c|c|c|}
\hline Probe & & Product designation & PCR result \\
\hline L01-13 & \multirow{24}{*}{ 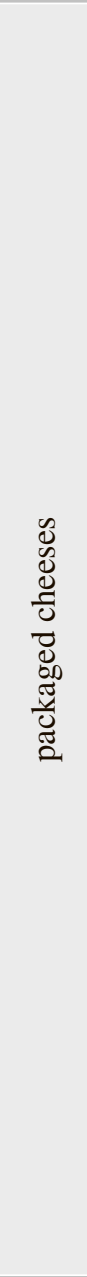 } & $\begin{array}{l}\text { King Cut Emmentaler AOP } \\
\text { (purchased in Asia, without casein tag) }\end{array}$ & pos \\
\hline L02-13 & & Grated cheese Emmentaler AOP & pos \\
\hline L03-13 & & Bio-Emmentaler AOP & pos \\
\hline L04-13 & & Emmentaler AOP surchoix & pos \\
\hline L05-13 & & Emmentaler AOP mild & pos \\
\hline L06-13 & & Emmentaler AOP surchoix & pos \\
\hline L08-13 & & Emmentaler AOP mild & pos \\
\hline L10-13 & & Gotthelf Emmentaler AOP & pos \\
\hline L11-13 & & Emmentaler AOP mild & pos \\
\hline L12-13 & & Emmentaler AOP surchoix & pos \\
\hline L13-13 & & Emmentaler AOP mild & pos \\
\hline L14-13 & & Emmentaler AOP surchoix & pos \\
\hline L17-13 & & Grated cheese Emmentaler AOP / Gruyère & pos \\
\hline L18-13 & & Grated cheese Emmentaler AOP BIO & pos \\
\hline L19-13 & & Emmental AOP surchoix & pos \\
\hline L24-13 & & Emmentaler AOP Eidgenoss, freshpack & pos \\
\hline L27-13 & & Emmentaler AOP, slices & pos \\
\hline L30-13 & & Grated cheese «Gruyère Emmental Raclette» & neg \\
\hline L33-13 & & Small cheese platter, pre-packaged & pos \\
\hline L35-13 & & Small cheese platter, pre-packaged & pos \\
\hline L37-13 & & Emmentaler AOP mild & pos \\
\hline L39-13 & & Grated cheese «Gruyère Emmentaler» & pos \\
\hline L44-13 & & Emmentaler AOP 6 months & pos \\
\hline L49-13 & & Emmentaler AOP extra & pos \\
\hline L25-13 & \multirow{14}{*}{ 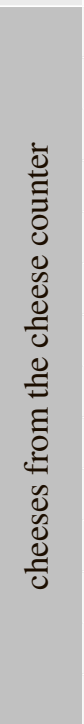 } & Emmentaler AOP mild & pos \\
\hline L50-13 & & Emmentaler AOP extra & pos \\
\hline L45-13 & & Emmentaler AOP mild & pos \\
\hline L46-13 & & Emmentaler AOP extra & pos \\
\hline L47-13 & & Emmentaler AOP extra & pos \\
\hline L48-13 & & Emmentaler AOP mild & pos \\
\hline L40-13 & & Emmentaler AOP & neg \\
\hline L41-13 & & Emmetnaler AOP mild & pos \\
\hline L42-13 & & Emmentaler AOP mild & pos \\
\hline L43-13 & & Emmentaler AOP mild & pos \\
\hline L36-13 & & Emmentaler AOP, cave-aged & pos \\
\hline L28-13 & & Emmentaler AOP & pos \\
\hline L31-13 & & Emmentaler AOP mild & pos \\
\hline L32-13 & & Emmentaler AOP mild & pos \\
\hline L16-13 & \multirow{4}{*}{ 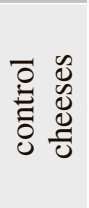 } & Chäs Schiibe (sliced cheese) & neg \\
\hline L07-13 & & Rahmtaler for the retailer Coop & neg \\
\hline L23-13 & & Allgäuer Emmentaler & neg \\
\hline L34-13 & & Wiesenkäse & neg \\
\hline L15-13 & \multirow{4}{*}{ 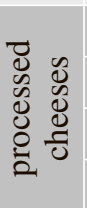 } & Emmentaler processed cheese Swiss-Style 12 portions & pos \\
\hline L20-13 & & Processed cheese Emmentaler & pos \\
\hline L21-13 & & Processed cheese Emmentaler & pos \\
\hline $\mathrm{L} 22-13$ & & Processed cheese Emmentaler & pos \\
\hline
\end{tabular}

[2] C. Bosley, 'How to Make Sure Those Holes Are Really Swiss', Bloomberg Businessweek, Bloomberg, 2014.

[3] L. Pillonel, S. Ampuero, R. Tabacchi, J. O. Bosset, Eur. Food Res. Technol. 2002, 216, 179.

[4] F. Camin, K. Wietzerbin, A. B. Cortes, G. Haberhauer, M. Lees, G. Versini, J. Agri. Food Chem. 2004, 52, 6592.

[5] L. Pillonel, R. Badertscher, P. Froidevaux, G. Haberhauer, S. Holzl, P. Horn, A. Jakob, E. Pfammatter, U. Piantini, A. Rossmann, R. Tabacchi, J. O. Bosset, Lebensmittel Wissenschaft und - Technologie - Food Science and Technology 2003, 36, 615.

[6] S. Cattaneo, J. A. Hogenboom, F. Masotti, V. Rosi, L. Pellegrino, P. Resmini, Dairy Sci. Technol. 2008, 88, 595.

[7] A. Gori, R. M. Maggio, L. Cerretani, M. Nocetti, M. F. Caboni, Int. Dairy J. 2012, 23, 115.

[8] L. Pillonel, U. Bütikofer, A. Rossmann, R. Tabacchi, J. O. Bosset, Mitt. Lebensmittel Hygiene 2004, 95, 489

[9] A. Galimberti, F. De Mattia, A. Losa, I. Bruni, S. Federici, M. Casiraghi, S. Martellos, M. Labra, Food Res. Int. 2013, 50, 55.

[10] I. Mafra, I. M. P. L. V. O. Ferreira, M. B. P. P. Oliveira, Eur. Food Res. Technol. 2008, 227, 649.

[11] G. Mauriello, L. Moio, A. Genovese, D. Ercolini, J. Dairy Sci. 2003, 86, 486.

[12] E. F. Arcuri, A. F. El Sheikha, T. Rychlik, I Piro-Métayer, D. Montet, Food Control 2013, 30,1 .

[13] M. S. Bloch, D. Paunescu, P. R. Stoessel, C. A. Mora, W. J. Stark, R. N. Grass, J. Agri. Food Chem. 2014, 62, 10615.

[14] M. G. Casey, D. Isolini, R. Amrein, D. Wechsler, H. Berthoud, Dairy Sci. Technol. 2008, 88, 457.

[15] G. Kielwein, H. K. Luh, 'Internationale Käse Kunde', Magnus Verlag Essen, Essen, 1979.

[16] J. Kammerlehner, 'Cheese Technology', Verlag Freisinger Künstlerpresse, 2009.

[17] R. K. Robinson, 'Dairy Microbiology handbook - The microbiology of milk and milk products', John Wiley and Sons, 2002.

[18] H. Berthoud, Patent Appl. No: WO 2011/039359 A2, 2011.

[19] A. Amrane, Enzyme Microb. Technol. 2001, 28, 827.

[20] R. Cachon, C. Divies, Appl. Microbiol. Biotechnol. 1994, 41, 694.

[21] R. Berkholz, D. Röhlig, R. Guthke, Enzyme Microb. Technol. 2000, 27, 784.

[22] H. Tse-Chao, L. Bao-Lin, Z. Hua, 'Freezedrying of pharmaceutical and food products', CRC Press, Boca Raton, 2010.

[23] C. P. Champagne, H. Detournay, M. J. E. Hardy, J. Ind. Microbiol. Biotechnol. 1991, 7, 147.

[24] A. S. Carvalho, J. Silva, P. Ho, P. Teixeira, F. X. Malcata, P. Gibbs, Int. Dairy J. 2004, 14, 835.

[25] A. Schoug, J. Fischer, H. Heipieper, J. Schnürer, S. Hakansson, J. Ind. Microbiol. Biotechnol. 2008, 35, 175 .

[26] F. J. Carr, D. Chill, N. Maida, Crit. Rev. Microbiol. 2002, 28, 281

[27] L. R. Rodrigues, J. A. Teixeira, R. Oliveira, Biochem. Engin. J. 2006, 32, 135.

[28] P. F. Bernàrdez, I. R. Amado, L. P. Castro, N. P. Guerra, Int. Dairy J. 2008, 18, 1057.

[29] A. S. Carvalho, J. Silva, P. Ho, P. Teixeira, F. X Malcata, P. Gibbs, Biotechnol. Prog. 2004, 20, 248.

[30] A. Siaterlis, G. Deepika, D. Charalampopoulos, Lett. Appl. Microbiol. 2009, 48, 295.

[31] K. Adamberg, S. Kask, T. Laht, T. M. Paalme, Int. J. Food Microbiol. 2003, 85, 171.

[32] E. Zannini, S. Santarelli, A. Osimani, L. Dell' Aquila, F. Clementi, Ann. Microbiol. 2005 55, 273.

[33] M. Saarela, I. Virkajarvi, H. L. Alakomi, T Mattila-Sandholm, A. Vaari, T. Suomalainen, J. Matto, J. Appl. Microbiol. 2005, 99, 1330. 